\section{Commentary: Angiotensin II: Expanding the rescue options for vasoplegia}

\author{
John G. Augoustides, MD, FASE, FAHA
}

Given the serious effects of vasoplegia on outcomes after cardiothoracic surgery, clinical rescue remains a priority in perioperative management. ${ }^{1,2}$ The knowledge gaps in the pathogenesis of this syndrome have prompted calls for further investigation to solve this complex puzzle, including the roles of the renin-angiotensin-aldosterone system. ${ }^{3-5}$

In this issue of the Journal, Chow and colleagues ${ }^{5}$ evaluate the evidence supporting angiotensin II for vasoplegic rescue in cardiothoracic surgery. The authors highlight the disordered kinetics in the renin-angiotensin-aldosterone system to provide a rationale for support of systemic vascular tome with angiotensin II. They also suggest dosing protocols for angiotensin II in the cardiothoracic setting, as well as avenues for future research.

How might this important work modify our approach to vasoplegia? First, angiotensin II is an important option for clinical rescue in refractory vasoplegic shock. ${ }^{5,6}$ Second, angiotensin II also may facilitate a significant reduction in total vasopressor dose. ${ }^{5}$ This vasopressor-sparing effect may minimize the ischemic risk by supporting a more balanced restoration of vascular tome. ${ }^{7-9}$

Although this report expands the therapeutic armamentarium for vasoplegia, it also highlights some important caveats with this vasopressor. ${ }^{5-9}$ The first caveat is that we know very little about adverse events associated with angiotensin II, owing to the limited evidence base..$^{5-8}$ Although the evidence has established angiotensin II as a therapeutic option in vasoplegia, further clinical trials are needed to delineate its therapeutic window. ${ }^{9}$ The second

\footnotetext{
From the Department of Anesthesiology and Critical Care, Perelman School of Medicine, University of Pennsylvania, Philadelphia, Pa.

Disclosures: The author reported no conflicts of interest.

The Journal policy requires editors and reviewers to disclose conflicts of interest and to decline handling or reviewing manuscripts for which they may have a conflict of interest. The editors and reviewers of this article have no conflicts of interest.

Received for publication March 24, 2021; revisions received March 24, 2021; accepted for publication April 8, 2021; available ahead of print April 20, 2021.

Address for reprints: John G. Augoustides, MD, FASE, FAHA, Cardiovascular and Thoracic Section, Department of Anesthesiology and Critical Care, Dulles 680, HUP, 3400 Spruce St, Philadelphia, PA 19104-4283 (E-mail: yiandoc@hotmail. com).

J Thorac Cardiovasc Surg 2022;163:1417-8

$0022-5223 / \$ 36.00$

Copyright (C) 2021 by The American Association for Thoracic Surgery

https://doi.org/10.1016/j.jtcvs.2021.04.014
}

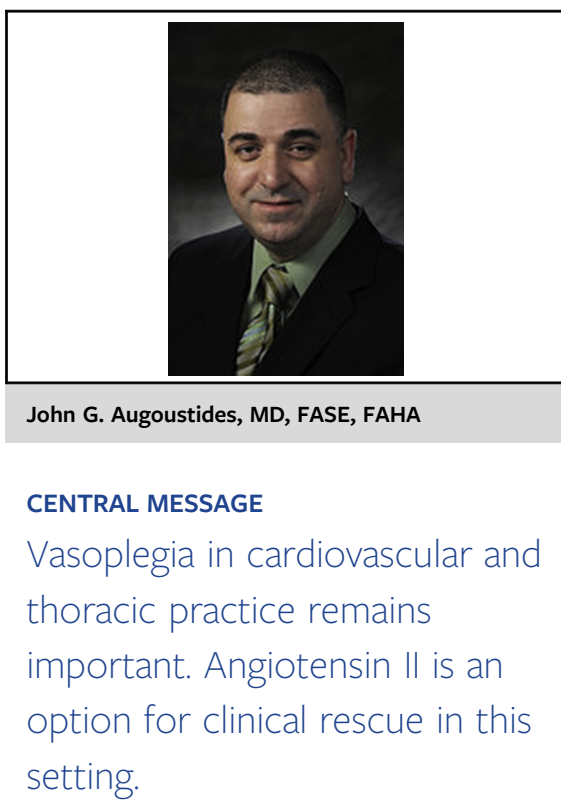

caveat is that the current evidence base has a distinct adult focus. ${ }^{5,6}$ Whereas vasoplegia remains an important syndrome in pediatric practice, the role and safety of angiotensin II in this clinical domain remain largely unknown. ${ }^{1,5}$

So where do we go from here? There is a critical mass of evidence to support further scientific inquiry both at the biochemical and bedside levels. ${ }^{3}$ Detailed investigation of the biochemical mechanisms may explain the observed efficacy of angiotensin II in vasoplegia, likely framed by the kinetics within the renin-angiotensin-aldosterone cascade. ${ }^{4-10}$ The bedside approach to inquiry would include further clinical trials to define the roles and safety of angiotensin II in the management of systemic vascular tome for both pediatric and adult cardiothoracic practice, perhaps with a focus on high-risk patients. ${ }^{5}$ These dual approaches are complementary and so together may offer us the best way to integrate angiotensin II into our clinical practice.

In conclusion, Chow and colleagues are to be congratulated for highlighting the promise of angiotensin as a rescue option for vasoplegia in cardiothoracic practice. They have emphasized the role and clinical implications of the reninangiotensin-aldosterone system in the complex puzzle of vasoplegia associated with cardiac surgery.

\section{References}

1. Sacks LD, Hollander SA, Zhang Y, Ryan KR, Ford MA, Maeda K, et al. Vasoplegia after pediatric cardiac transplantation in patients supported with a continuous flow ventricular assist device. J Thorac Cardiovasc Surg. 2019;157: 2433-40.

2. Guarracino F, Habicher M, Treskatsch S, Sander M, Szekely A, Paternoster G, et al. Vasopressor therapy in cardiac surgery—an experts' consensus statement. J Cardiothorac Vasc Anesth. 2021;35:1018-29. 
3. Lo Rito M. Commentary: "Where the telescope ends, the microscope begins Which of the two has the grander view?" What we should be using to look at vasoplegia. J Thorac Cardiovasc Surg. 2019;157:2441-2.

4. Beaver TM, Ahsan Ejaz A. Commentary: renin-angiotensin system inhibitor and cardiac surgery: "more than meets the eye." Semin Thorac Cardiovasc Surg. February 18, 2021 [Epub ahead of print].

5. Chow JH, Wittwer ED, Wieruszewski PM, Khanna AK. Evaluating the evidence for angiotensin II for the treatment of vasoplegia in critically ill cardiothoracic surgery patients. J Thorac Cardiovasc Surg. 2022;163: 1407-14.

6. Shaefi A, Mittel A, Klick J, Evans A, Ivascu NS, Gutsche J, et al. Vasoplegia after cardiovascular procedures-pathophysiology and targeted therapy. J Cardiothorac Vasc Anesth. 2018:32:1013-22.
7. Klijian A, Khanna AK, Reddy VS, Friedman B, Ortoleva J, Evans AS, et al Treatment with angiotensin II is associated with rapid blood pressure response and vasopressor sparing in patients with vasoplegia after cardiac surgery: a post-hoc analysis of angiotensin II for the treatment of high-output shock (ATHOS-3) study. J Cardiothorac Vasc Anesth. 2021;35:51-8.

8. Papazisi O, Palmen M, Jan Dansen AH. The use of angiotensin II for the treatment of post-cardiopulmonary bypass vasoplegia. Cardiovasc Drugs Ther. October 21, 2020 [Epub ahead of print].

9. Chow JH, Strauss E, Mazzeffi MA. Angiotensin II and vasoplegia in cardiac surgery: paradigm changer or costly contender? J Cardiothorac Vasc Anesth. 2021;35:59-60.

10. Trethowan B, Michaud CJ, Fifer S. Use of angiotensin II in severe vasoplegia after left pneumonectomy requiring cardiopulmonary bypass: a renin response analysis. Crit Care Med. 2020;48:e912-5. 